\title{
Patient empowerment and multimodal hand hygiene promotion: a win-win strategy.
}

\author{
Maryanne McGuckin \\ Thomas Jefferson Medical College \\ Julie Storr \\ World Health Organization \\ Yves Longtin \\ Centre de recherche en infectiologie du CHUL \\ Benedetta Allegranzi \\ University of Verona \\ Didier Pittet \\ University of Geneva Hospitals and Faculty of Medicine \\ Follow this and additional works at: https://jdc.jefferson.edu/healthpolicyfaculty \\ Part of the Health Services Research Commons \\ Let us know how access to this document benefits you
}

\section{Recommended Citation}

McGuckin, Maryanne; Storr, Julie; Longtin, Yves; Allegranzi, Benedetta; and Pittet, Didier, "Patient empowerment and multimodal hand hygiene promotion: a win-win strategy." (2011). College of Population Health Faculty Papers. Paper 49.

https://jdc.jefferson.edu/healthpolicyfaculty/49

This Article is brought to you for free and open access by the Jefferson Digital Commons. The Jefferson Digital Commons is a service of Thomas Jefferson University's Center for Teaching and Learning (CTL). The Commons is a showcase for Jefferson books and journals, peer-reviewed scholarly publications, unique historical collections from the University archives, and teaching tools. The Jefferson Digital Commons allows researchers and interested readers anywhere in the world to learn about and keep up to date with Jefferson scholarship. This article has been accepted for inclusion in College of Population Health Faculty Papers by an authorized administrator of the Jefferson Digital Commons. For more information, please contact: JeffersonDigitalCommons@jefferson.edu. 


\title{
As submitted to:
}

\author{
American Journal of Medical Quality
}

\author{
And later published as:
}

\section{Patient empowerment and multimodal hand hygiene}

\author{
promotion: a win-win strategy
}

\section{Jan-Feb 2011 26(1), pp.10-17}

\section{DOI: 10.1177/1062860610373138}

Maryanne McGuckin, Dr. ScED, ${ }^{\mathrm{a}, \mathrm{b}}$ Julie Storr, BN, MBA, ${ }^{\mathrm{c}, \mathrm{d}}$ Yves Longtin, MD, Benedetta Allegranzi, MD, ${ }^{\mathrm{d}}$ Didier Pittet, $\mathrm{MD}, \mathrm{MS}^{\mathrm{d}, \mathrm{e}}$

a) McGuckin Methods International, Ardmore, PA, USA

b) Thomas Jefferson Medical College, Philadelphia, PA, USA

c) National Patient Safety Agency, London, UK

d) World Health Organization, World Alliance for Patient Safety First Global Patient

Safety Challenge, Geneva, Switzerland

e) Infection Control Program, University of Geneva Hospitals and Faculty of Medicine,

Geneva, Switzerland

Submitted to: American Journal of Medical Quality 
Word count (excluding abstract, references, table, figure): 2969

\section{Corresponding author:}

Dr. Maryanne McGuckin

President, McGuckin Methods International

Senior Scholar, Health Policy, Thomas Jefferson Medical College

115 E. Athens Ave.

Ardmore, PA 19003

Tel.: (610) 304-2927; fax: (610) 649-2960

Email: mcguckin@hhreports.com

\section{Abstract}

Patient empowerment is a new concept in health care that has now been extended to the domain of patient safety. Within the framework of the development of the new World Health Organization (WHO) Guidelines on Hand Hygiene in Health Care, we conducted a review of the literature from 1997 to 2008 to identify the evidence supporting programs aimed at encouraging patients to take an active role in their care. Patient empowerment is an integral part of the WHO hand hygiene multimodal strategy. Hand hygiene promotion strategies that have demonstrated evidence of successfully empowering patients include one or all of the following components: educational tools, motivation and reminder tools, and role modelling. Importantly, programs and models for empowering patients must be developed with an inbuilt evaluation component that includes both qualitative and quantitative measures to determine not only what works, but under what conditions, and within which organizational context.

Word count: 148 


\section{Introduction}

Patient empowerment is a relatively new concept in healthcare that has been expanded to the field of patient safety. In developed countries, such as United States and the United Kingdom, the introduction of this concept has been influenced significantly by the revolutionary USA Institute of Medicine reports on health quality and safety. ${ }^{1,2}$ Of particular note is their novel focus on increasing public awareness of medical errors and national efforts to actively engage patients in their own care. ${ }^{1,2}$ The term "empowerment" can have different meanings and interpretations, but in healthcare it refers generally to the process that allows an individual or a community to gain the knowledge, skills, and attitudes needed to make choices and participate in their care. ${ }^{3}$ However, there are many unanswered questions on how to tailor the approach to best suit needs and goals. Questions that represent a particular challenge to policy-makers and implementers of this strategy are: what is the most appropriate terminology to encourage patient engagement? What is the evidence to support its effectiveness and its possible impact on patient outcome? Are patients really interested in empowerment? What are the barriers to patient empowerment? How is empowerment viewed from a healthcare worker $(\mathrm{HCW})$ perspective and what is his/her role? All these issues can be summed up in one final question: what is the best way to develop and implement an empowerment program?

This review presents the evidence from the current literature supporting the use of programs aiming to encourage patients to take a more active role in their care, especially with regards to hand hygiene promotion. It also proposes a multifaceted strategy for 
empowerment that can be incorporated into a broader, multimodal, hand hygiene improvement strategy.

\section{Methods}

\section{Search strategy and selection criteria}

We performed a Medline search of all English-language papers published between January 1997 and December 2008 using the following keywords alone and in various combinations: "patient participation"; "involvement"; "empowerment"; "education"; “decision-making"; "professional-patient relations"; and "hand hygiene". A total of 1502 publications were retrieved. Reference lists were manually scanned to identify any other relevant documentation. The search yielded 133 full papers and three abstracts from scientific proceedings on patient empowerment and hand hygiene. Each one was reviewed using the following criteria: 1) type of study; 2) demographics; 3) intervention; 4) outcomes; 5) summary of findings; and 6) relevance to empowerment, hand hygiene, and evidence-based programs.

\section{Results}

Patient empowerment definition and terminology

The World Health Organization (WHO) defines empowerment as "a process through which people gain greater control over decisions and actions affecting their health" and should be seen as both an individual and a community process. ${ }^{4}$ However, the term chosen to define this process will depend on what is appropriate for the specific culture of a region or community. Although "patient empowerment" might be the preferred term 
from a patient advocacy point of view as it gives a stronger emphasis to the role of patients, the less emotionally charged and challenging term "patient participation" might be a more acceptable term to many HCWs, patients, and cultures. For the purpose of this review, the word "empowerment" is used.

Four components have been reported as being fundamental to the process of patient empowerment: 1) Patient participation in which there is an understanding and acceptance by the patient of his/her opportunity to become involved in the care process and contribute to a safer delivery of healthcare. ${ }^{5}$ Key characteristics such as age, culture, background, personality, and level of intelligence have been identified as factors that impact on success when engaging patients in participations and form the foundation of empowerment. ${ }^{6}$ 2) Patient knowledge in which patients are given sufficient knowledge including risk and actionable patient steps to help them engage in decisions with their healthcare provider. ${ }^{5}$ Patients usually prefer information/knowledge that is specific, given by their HCWs, and printed for use as prompt sheets if necessary. ${ }^{7}$ 3) Patient skills which include self-efficacy and health literacy thereby helping the patient not only understand the issues but also believing they can attain a positive goal if they participate in their care. These skills have been linked to better performance of a task that requires a change in behavior. ${ }^{8}$ 4) Facilitating environment that encourages patients to develop and practice open communication about their care in an environment free of barriers. ${ }^{5}$ In order to create this environment, $\mathrm{HCW}$ s must also be empowered by providing them with a workplace that promotes empowerment and recognizes that the relationship and communication of HCWs with patients can be powerful. ${ }^{9}$ Based on these four components, "empowerment" can be defined as: a process in which patients understand 
their opportunity to contribute, and are given the knowledge and skills by their healthcare provider and other educational sources to perform a task in an environment that recognizes community and cultural differences and encourages patient participation. ${ }^{10}$

\section{$\underline{\text { Hand hygiene compliance and empowerment }}$}

Multimodal programs aimed at increasing hand hygiene compliance are now considered as the most reliable, evidence-based method for ensuring sustainable improvement ${ }^{10-11}$ and are recommended by WHO in its recently published guidelines. ${ }^{10}$ Among other recommendations, these guidelines explicitly invite healthcare settings to foster a sense of empowerment in their patients. WHO has developed and tested a multimodal hand hygiene improvement strategy ${ }^{10}$ to translate these guidelines into practice that includes the concept of patient empowerment. Through this vehicle, the organization is committed to promote initiatives aimed at informing and educating patients about the importance of hand hygiene and their potentially powerful role in supporting improvement. $^{12}$ This is mirrored across a growing number of countries, e.g., Australia, Belgium, Canada, England and Wales, Ireland, Italy, Northern Ireland, Norway, Ontario (Canada), and Saudi Arabia, that are incorporating patient empowerment into their national hand hygiene promotion campaigns. In the USA, in the absence of a nationwide hand hygiene promotion campaign, the Centers for Disease Control and Prevention (http://www.cdc.gov/) provides some guidance for encouraging patient to participate actively in healthcare-associated infection prevention.

\section{$\underline{\text { Patient and HCW empowerment }}$}


The extent to which patients wish to be empowered is still a matter of debate. Miller and Farr $^{13}$ assessed patients' knowledge of HAI in the USA by asking if they were satisfied with the information they received about HAI and if they were willing to pay for an increased investment in infection control programs within their hospital. Responses revealed that $70 \%$ of patients were concerned about the risk of HAI, $69 \%$ reported that the risk was never explained, and 57\% stated that they would be willing to pay for improved infection control programs and information on HAI.

The National Patient Safety Agency for England and Wales assessed patients' views on involvement as part of their "cleanyourhands" campaign, and reported that $71 \%$ of respondents wanted to be involved in improving hand hygiene practices. ${ }^{14}$ Similar results were reported by an acute care trust, ${ }^{15}$ where $79 \%$ of patients thought that they should be involved in hand hygiene improvement. In studies conducted in the USA and the UK, McGuckin and colleagues ${ }^{16-18}$ reported on patients' willingness to be empowered and involved in hand hygiene by asking their HCWs to clean their hands. However, although $80-90 \%$ of patients will agree to ask in principle, the percentage of those who actually asked their HCW is slightly lower at 60-70\%. A recent survey of consumers on their attitudes about hand hygiene found that four out of five consumers said they would ask their HCW "did you wash/sanitize your hands?" if their HCW educated them on the importance of hand hygiene. ${ }^{19}$ Similar findings were reported from a survey conducted in a Swiss hospital. ${ }^{20}$ Only a quarter of patients would be willing to remind HCWs to perform hand hygiene; however, this proportion rose significantly to more than $80 \%$ if patients were explicitly authorized to do so by their HCWs. ${ }^{20}$ In a telephone survey of US patients, only $45 \%$ were "very comfortable" to ask HCWs whether they have washed 
their hands. ${ }^{21}$ Another survey of 80 patients in a surgical department in the UK reported that most would probably not ask HCWs if they had washed their hands. ${ }^{22}$

Willingness to be empowered is dependent on patient input during the development of the program. Entwistle and colleagues ${ }^{23}$ reviewed the content of five leading patient safety directives in the USA. They reported that the programs had been developed without input from patients and lacked information about what the HCWs needed to do and what support should be given to patients. In 2001, the National Patient Safety Foundation Advisory Council in the USA took up the concern about consumer involvement and developed a new program with input from patients and families, "Patients and families in patient safety: nothing about me, without me", as a call to action for healthcare organizations at all levels to involve patients and families in systems and patient safety problems. $^{24}$

In 2004, WHO launched the World Alliance for Patient Safety to raise awareness and political commitment to improve the safety of healthcare in all Member States. A specific program of work, Patients for Patient Safety, was designed to ensure that the wisdom of patients, families, consumers, and citizens, in both developed and developing countries, is central in shaping the work of the Alliance. In 2007, WHO conducted a two-part survey on patient empowerment to gain further knowledge and to incorporate geographically and culturally diverse perspectives related to empowerment into the final version of the WHO Guidelines for Hand Hygiene in Healthcare. ${ }^{10}$ Survey results can be found at: http://www.who.int/patientsafety/hand_hygiene_survey_phase1.pdf. One of the key findings was that HCWs' active encouragement to the patient about reminding them about hand hygiene had a significant impact on a patient's willingness to be empowered. 


\section{$\underline{\text { Barriers to patient empowerment }}$}

There are several different theories from various disciplines that provide insight into the potential barriers to patient empowerment in the field of hand hygiene in healthcare. These theories include cognitive, behavioral, social, marketing, and organizational theories that may be valuable when considering barriers to be overcome, or a strategy to involve and engage patients. ${ }^{25}$ Pittet $^{26}$ discusses the promising perspective of the theory of ecological perspective as part of a multimodal program to increase hand hygiene compliance. According to this theory, behavior is viewed as affecting and being affected by multiple factors and is influenced by the social environment. A significant factor often perceived by the patient is the fear of a negative impact/response from their HCWs. ${ }^{20,27}$ This barrier was explored in an acute care rehabilitation unit where patients are often dependent on their HCWs for activities of daily living. ${ }^{18}$ The authors reported that $75 \%$ of patients were comfortable asking their HCWs "did you wash/sanitize your hands?" It is important to note that empowerment is a major part of the rehabilitation process, and therefore, this may have been a motivating factor for empowerment in these patients. Acknowledging different views on patient empowerment and dealing with them in the context of an organization, culture, or community will be necessary when removing barriers to patient empowerment, involvement or participation in hand hygiene compliance.

Programs and models of hand hygiene promotion including patients and healthcare worker empowerment 


\section{Evidence}

As only a few studies have been published to assess the efficacy of patient empowerment to improve hand hygiene, an evidence-based review of programs that have empowered, involved or encouraged patient participation in hand hygiene promotion cannot be conducted by the traditional method focused on quantitative data, linear causality, and "scientific" reliability. ${ }^{28}$ Therefore, the following review of programs that have used empowerment has been limited to published articles and reports in which there was some form of evaluation for hand hygiene as a separate outcome or as part of a multifaceted program.

\section{$\underline{\text { Educational programs }}$}

Hand hygiene information for patients can be printed material, oral demonstration, or by audiovisual means. In their patient empowerment model, McGuckin and colleagues educated patients about hand hygiene by using brochures that asked the patient to be a partner with their HCWs. ${ }^{16-18}$ These materials included information about who, why, where and when hand hygiene should be performed. This program has been evaluated in several multicenter studies documenting that $80-90 \%$ of patients reported that they had read the educational brochures.

Petersen and colleagues ${ }^{29}$ developed a promotional campaign that included educational brochures for patients on hand hygiene, as well as the distribution of alcoholbased handrub. Although patients were encouraged to speak up about hand hygiene, they 
reported an overall increase of only $10 \%$ in $\mathrm{HCW}$ compliance, but believed this was attributable to limitations in their observation technique.

Demonstrations as a form of education and empowerment about hand hygiene were shown to increase awareness and compliance. ${ }^{30}$ Chen and Chiang compared the use of a hand hygiene video and illustrated posters to teach hand hygiene to parents of pediatric intensive care patients and to empower them about their role in hand hygiene. ${ }^{31}$ They reported a steady sustained increase in parents' compliance and empowerment using both educational strategies. These results were attributed to a strong motivation to protect their child.

In 2008, the Centers for Disease Control and Prevention released a podcast on hand hygiene and patient empowerment stating that it is appropriate to ask or remind healthcare providers to practice hand hygiene (http://www2c.cdc.gov/podcasts/player.asp). Empowering patients about patient safety issues using internet sources such as home pages for hospitals or national agencies has become part of many hospital systems as a result of mandatory reporting of quality and safety. When 32 consumer participants were introduced to five internet sources on quality care to educate them about patient involvement, a significant improvement in test scores after exposure to these sources was observed. ${ }^{32}$

\section{$\underline{\text { Reminders and motivational messages }}$}

Patient empowerment models often include visual reminders for both the HCW and the patient $^{16-18}$ and usually include small badges or stickers worn by patients with a message such as "did you wash/sanitize your hands?" A multicenter, one-year evaluation of a 
model using education and reminders as tools to empower inpatients found a statistically significant increase in hand hygiene compliance, regardless of hospital size and unit type. $^{33}$

Posters, another form of reminder, are used in hand hygiene programs and campaigns to educate and empower HCWs as well as patients. An evaluation of 69 hand hygiene posters representing 75 messages found that only $41 \%$ framed the message for motivation, empowerment, and health promotion. ${ }^{34}$ Similar findings were reported from a poster campaign in a pediatric ICU to encourage both HCWs and patients/visitors to practise hand hygiene. ${ }^{35}$ It was shown that if the message is framed correctly, posters can serve as a visual reminder and encouragement for both the patient and the HCW to participate in hand hygiene practices. Lent and colleagues reported an increase in willingness to ask about hand hygiene when positive messages such as "thank you for practising hand hygiene" and reminders that said "thanks for washing" were used to support patient empowerment. ${ }^{36}$ However, based on similar studies, others have come to a different conclusion. For example, Julian and colleagues evaluated the use of posters to empower HCWs and patients and concluded that posters alone are insufficient to achieve the goal. ${ }^{37}$ Interestingly, they also reported that most HCWs stated that they did not mind being reminded about hand hygiene. Educational videos, posters, brochures, and visual reminders targeted to educate HCWs and patients were evaluated in three long-term care facilities as part of a comprehensive hand hygiene program. ${ }^{38}$ This combination of HCW education and patient empowerment resulted in an aggregate increase in hand hygiene compliance of $52 \%$ and a $32 \%$ decrease in infections. ${ }^{38}$ 


\section{$\underline{\text { Role modelling }}$}

HCWs' behavior towards hand hygiene is influenced by either peers or superiors. The effect of the so-called "role modelling" including the promotion of patient empowerment has been shown to influence compliance and motivate the patient to be empowered. McGuckin and colleagues reported an increase in hand hygiene compliance and alcoholbased hand rub consumption by using "authority figures" as role models for

empowerment. ${ }^{39}$ The medical director, nurse manager, director of nursing, and infection control professionals dedicated to the medical/surgical intensive care units (ICU) recorded short audio messages about hand hygiene, such as "we want $100 \%$ compliance with hand hygiene in our ICU" and "remember to use sanitizer", that were broadcast at randomly timed intervals from the announcement speakers at the nurses' station.

Christensen and Taylor question the use of empowerment in the case of ICU patients and suggest that patients should have control restored before they can be empowered. ${ }^{40}$ Lankford and colleagues $^{41}$ reported that a HCW's hand hygiene behavior was influenced negatively when the $\mathrm{HCW}$ was in a room with a senior staff member or peer who did not perform hand hygiene. Sax and colleagues ${ }^{42}$ identified the influence of superiors and colleagues on staff and patients as highly ranked determinants of good hand hygiene adherence.

Template for incorporating patient empowerment into a multimodal hand hygiene program in healthcare facilities and communities 
The prerequisite for the successful implementation of a patient empowerment program is its integration in an institutional multimodal hand hygiene promotion strategy (Table) and this is considered a type IA evidence-based recommendation in the most recent WHO Guidelines for Hand Hygiene in Health Care. ${ }^{10}$ Patient/HCW empowerment programs should be part of any basic multimodal hand hygiene improvement strategy. The strategy proposed by WHO to implement the Guidelines on Hand Hygiene includes five key elements, the fifth of which is the creation of an Institutional Safety Climate. In this context, partnership with patients and their relatives and with patient organizations can facilitate the achievement of this goal. In addition, the fourth element in a multimodal strategy, reminders in the workplace, can be applied by empowering patients to act as reminders to $\mathrm{HCWs}$ about hand hygiene and can be incorporated into a multimodal strategy by following the five step process (Figure). There is substantial evidence to suggest that patients can be empowered and actually help improve HCWs' hand hygiene compliance. The foundation of a process must be ownership, accountability and shared responsibility. It is important that any hand hygiene improvement program is developed within the culture of the institution and with support from key stakeholders. Barriers to empowerment must be identified and can often be addressed by making sure HCWs are empowered so they can in turn provide the explicit education needed to empower their patients. It is of the utmost importance to embed an evaluation component in programs and models aimed at empowering patients and HCWs. It should include both qualitative and quantitative measures to determine not only what elements best work, but also under what conditions, and within which organizational context. 
In addition to the easy-to-follow template, additional educational and interventional resources for implementation can be found at: http://whqlibdoc.who.int/publications/2009/9789241597906_eng.pdf.

\section{Summary}

Hand hygiene promotion strategies showing evidence of successful patient and HCW empowerment are usually part of a multifaceted approach and include at least one of the following elements: educational tools, motivation tools, and role modelling. They also include giving explicit permission to the patient to remind the HCW about hand hygiene. Finally, empowerment programs were implemented almost exclusively in healthcare settings in developed countries. Thus, it is important that further testing and implementation be undertaken and evaluated, particularly in diverse cultural contexts and in settings with limited resources. 


\section{Acknowledgments}

We thank Michal Frances, John Govednik, MS, Rachel Heath, BA, MScEcon, and Susan

Sheridan, MIM, MBA, for their assistance in the preparation and review of this

manuscript. Thanks also to the members of the WHO First Global Patient Safety

Challenge "Clean Care is Safer Care" core group (lead, Didier Pittet, MD, MS): John

Boyce, MD, Barry Cookson, Nizam Damani, Don Goldmann, MD, Lindsay Grayson,

Elaine Larson, PhD, RN, Geeta Mehta, MD, MAMS, FIAMS, Ziad Memish, MD,

FRCPC, FACP, Hervé Richet, Manfred Rotter, Syed Sattar, PhD, Hugo Sax, Wing Hong

Seto, Andreas Voss, and Andreas Widmer, MD, MS. We are indebted to Rosemary

Sudan for expert editorial assistance.

\section{Disclaimer}

WHO takes no responsibility for the information provided or the views expressed in this paper.

\section{Conflict of interest}

The authors report no conflicts of interest. 


\section{References}

1. Kohn L, Corrigan JM, Donaldson MS. (eds.). To err is human: building a safer health system. Washington, DC: Committee on Quality of Health Care in America, Institute of Medicine, National Academic Press, 2000.

2. Committee on Quality of Health Care in America, Institute of Medicine. Crossing the quality chasm: a new health system for the 21 st century. Washington, DC: National Academic Press, 2001.

3. Lau DH. Patient empowerment - a patient-centered approach to improve care. Hong Kong Med J 2002;8:372-74.

4. Health promotion glossary. Geneva, Switzerland: World Health Organization, 1998.

5. Angelmar R, Berman PC. Patient empowerment and efficient health outcomes. In: Cox, P. (ed.). Financing sustainable healthcare in Europe: new approaches for new outcomes (http://www.sustainhealthcare.org/cox.php)

6. Lyons M. Should patients have a role in patient safety? A safety engineering view. Qual Saf Health Care 2007; 16:140-42.

7. Currie K, Rajendran, Spink J, Carter M, Anderson J. Consumer health information: what the research is telling us. Aust Fam Physician 2001; 30:1108-11.

8. Bandura A. Social foundations of thought and action. Englewood Cliffs, NJ; Prentice Hall, 1986.

9. Manojlovich M. Power and empowerment in nursing: looking backward to inform the future. OIJN 2007;12 (available at: http://nursingworld.org/MainMenuCategories/ANAMarketplace/ANAPeriodi cals 
10. World Health Organization. WHO Guidelines on Hand Hygiene in Health Care.

Geneva, Switzerland: World Health Organization, 2009

11. Pittet D, Hugonnet S, Harbarth S, Mourouga P, Sauvan V, Touveneau S, Perneger

TV. Effectiveness of a hospital-wide programme to improve compliance with hand hygiene. Lancet 2000; 356:1307-12.

12. World Health Organization. Information sheet 4: patient and public involvement in hand hygiene improvement (available at http://www.who.int/gpsc/tools/Infsheet4.pdf.)

13. Miller PJ, Farr BM. Survey of patients' knowledge of nosocomial infections. Am J Infect Control 1989;17:31-34.

14. Cleanyourhands campaign. London: National Patient Safety Agency, 2007

(http://www.npsa.nhs.uk/cleanyourhands/about-us/patient-involvement/).

15. Duncanson V. A study of the factors affecting the likelihood of patients participating in a campaign to improve staff hand hygiene. Br J Infect Control, 2005;6:2630.

16. McGuckin M, Waterman R, Porten L, Bello S, Caruso M, Juzaitis B, et al. Patient education model for increasing handwashing compliance. Am J Infect Control, 1999, 27:309-14.

17. McGuckin M, Waterman R, Storr J, Bowler M, Ashby M, Topley K, et al. Evaluation of a patient-empowering hand hygiene programme in the UK. J Hosp Infect 2001;48:222-27. 
18. McGuckin M, Taylor A, Martin V, Porten L, Salcido R. Evaluation of a patient education model for increasing hand hygiene compliance in an in-patient rehabilitation unit. Am J Infect Control 2004;32:235-58.

19. McGuckin M, Waterman R, Shubin A. Consumer attitudes about health care-acquired infections and hand hygiene. Am J Med Quality 2006;21:342-46.

20. Longtin Y, Sax H, Allegranzi B, Hugonnet S, Pittet D. Patients' beliefs and perceptions of their participation to increase staff compliance with hand hygiene. Infect Control Hosp Epidemiol 2009 (in press).

21. Waterman AD, Gallagher T, Garbutt J, Waterman BM, Fraser V, Burroughs TE,. Hospitalized patients' attitudes about and participation in error prevention. J Gen Int Med 2006;21:367-79.

22. Davis RE, Koutantji M, Vincent CA. How willing are patients to question healthcare staff on issues related to the quality and safety of their healthcare? An exploratory study. Qual Saf Health Care 2008;17;90-96

23. Entwistle VA. Mello MM, Brennan TA. Advising patients about patient safety: current initiatives risk shifting responsibility. J Qual Pat Saf 2005;31:483-94.

24. National Patient Safety Foundation. Patient and Family Advisory Council report. National agenda for action: patients and families in patient safety. "Nothing about me, without me". Chicago, IL: National Patient Safety Foundation 2003:1-12.

25. Howe A. Can the patient be on our team? An operational approach to patient involvement in interprofessional approaches to safe care. J Interprof Care 2006;20:527-34. 
26. Pittet D. Behavior in infection control. J Hosp Infect 2004;58:1-13.

27. Williams T. Patient empowerment and ethical decision making. The patient/partner and the right to act. Dimen Crit Care Nurs 2002; 21:100-04.

28. Nutbeam, D. The challenge to provide 'evidence' in health promotion. Health Prom Int 1999;14:99-101.

29. Petersen K, Herman A, Sturm L, Grossno K, Friedman C. "Washed up and proud of it": hand hygiene promotional campaign. $17^{\text {th }}$ Annual Meeting of the Society for Healthcare Epidemiology in America, Baltimore, MD, 14-17 April 2007: abstract no. 11-153.

30. Riolo L. Effects of modeling errors on the acquisition and retention of sterile hand washing task. Percept Mot Skills 1997;84:19-26.

31. Chen Y-C, Chiang, L-C. Effectiveness of hand-washing teaching programs for families of children in paediatric intensive care units. J Crit Nurs 2007;16:1173-79.

32. Oermann MH, Lesley M, Kuefler SF. Using the internet to teach consumers about quality care. J Qual Imp 2002;28:83-9.

33. McGuckin M, Waterman R, Govednik J. Hand hygiene compliance rates in the US a one-year multicenter collaborative using product/volume usage measurement. Am J Med Qual 2009;24:205-213.

34. Jenner EA, Jones F, Fletcher BC, Miller L, Scott GM. Hand hygiene posters: motivators or mixed messages? J Hosp Infect 2005; 26:218-25. 
35. Reynolds L, Liverman T, Jacobs D, Bearman G, Edmond M. A creative yet simple approach to improve hand hygiene compliance in the pediatric intensive care unit. Am J Infect Control 2005;33:156-57.

36. Lent V, Eckstein E, Cameron A, Budavich R, Eckstein BA, Dunskey C. Evaluation of patient participation in a patient empowerment initiative to improve hand hygiene practices in a Veterans Affairs medical center. Am J Infect Control 2009;37:117-20.

37. Julian, Kathleen G, Subramanian, K, Brumbach, A, Whitener, CJ. Attitudes of healthcare workers and patients toward individualized hand hygiene reminders. Infect Control Hosp Epidemiol 2008; 29:781-82.

38. McGuckin M, Porten L, Schmidt R, Streed S. Validation of a comprehensive infection control program in ltc. Director 2004;12:14-17.

39. McGuckin M, Shubin A, McBride P, Lane S, Strauss K, Butler D, et al. The effect of random voice hand hygiene messages delivered by medical, nursing, and infection control staff on hand hygiene compliance in intensive care. Am J Infect Control 2006;34:673-75.

40. Christensen M, Hewitt-Taylor J. Patient empowerment: does it still occur in the ICU? Intens Crit Care Nurs 2007;23:156-61.

41. Lankford MG, Zembower TR, Trick WE, Hacek DM, Noskin GA, Peterson LR. Influence of role models and hospital design on hand hygiene of health care workers. Emer Inf Dis 2003; 9:217-23. 
42. Sax H, Uckay, I, Richet, H, Allegranzi, B, Pittet, D. Determinants of good adherence to hand hygiene among healthcare workers who have extensive exposure to hand hygiene campaigns. Infect Control Hosp Epidemiol 2007; 28:1267-74. 
Table. Prerequisites for successful hand hygiene promotion: a multimodal strategy

Prerequisites for successful hand hygiene promotion: a multimodal strategy

\begin{tabular}{|c|c|c|}
\hline $\begin{array}{l}\text { Key strategy } \\
\text { component }\end{array}$ & Definition & Essential elements \\
\hline System change & $\begin{array}{l}\text { Ensuring that the necessary } \\
\text { infrastructure is in place to } \\
\text { allow health-care workers to } \\
\text { practice hand hygiene }\end{array}$ & $\begin{array}{l}\text { Readily accessible alcohol- } \\
\text { based handrub at the point } \\
\text { of care } \\
\text { - Access to a safe, } \\
\text { continuous water supply as } \\
\text { well as soap and towels }\end{array}$ \\
\hline Training/education & $\begin{array}{l}\text { Providing regular training on } \\
\text { the importance of hand hygiene } \\
\text { based on the WHO "My five } \\
\text { moments for hand hygiene" } \\
\text { approach and the correct } \\
\text { procedures for handrubbing and } \\
\text { handwashing to all health-care } \\
\text { workers }\end{array}$ & $\begin{array}{l}\text { Establish robust education } \\
\text { programs for trainers, } \\
\text { observers and health-care } \\
\text { workers } \\
\text { - } \\
\text { Special sessions for newly } \\
\text { recruited staff } \\
\text { - } \\
\text { Regular updates for } \\
\text { previously trained staff }\end{array}$ \\
\hline $\begin{array}{l}\text { Evaluation and } \\
\text { feedback }\end{array}$ & $\begin{array}{l}\text { Monitoring hand hygiene } \\
\text { practices and infrastructure, } \\
\text { together with related } \\
\text { perceptions and knowledge } \\
\text { among health-care workers, and } \\
\text { providing performance and } \\
\text { results' feedback to staff }\end{array}$ & $\begin{array}{l}\text { - Hand hygiene compliance } \\
\text { monitoring through direct } \\
\text { observation } \\
\text { - } \\
\text { Alcohol-based handrub } \\
\text { consumption monitoring } \\
\text { - Knowledge evaluation after } \\
\text { education } \\
\text { - } \\
\text { Regular reports including } \\
\text { results of evaluation }\end{array}$ \\
\hline $\begin{array}{l}\text { Reminders in the } \\
\text { workplace }\end{array}$ & $\begin{array}{l}\text { Prompting and reminding } \\
\text { health-care workers about the } \\
\text { importance of hand hygiene and } \\
\text { the appropriate indications and }\end{array}$ & $\begin{array}{l}\text { Posters on hand hygiene } \\
\text { indications and correct } \\
\text { technique to handwash and } \\
\text { handrub at the point of }\end{array}$ \\
\hline
\end{tabular}




\begin{tabular}{|c|c|c|}
\hline & procedures for performing it & $\begin{array}{l}\text { patient care } \\
\text { - Distribution of other } \\
\text { reminders (e.g. pocket } \\
\text { leaflets, badges, stickers) to } \\
\text { health-care workers } \\
\text { - } \\
\text { Regular renewal of } \\
\text { reminders }\end{array}$ \\
\hline $\begin{array}{l}\text { Institutional safety } \\
\text { climate }\end{array}$ & $\begin{array}{l}\text { Creating an environment and } \\
\text { perceptions that facilitate } \\
\text { awareness-raising of patient } \\
\text { safety issues to foster the } \\
\text { consideration of hand hygiene } \\
\text { improvement as a high priority } \\
\text { at all levels }\end{array}$ & 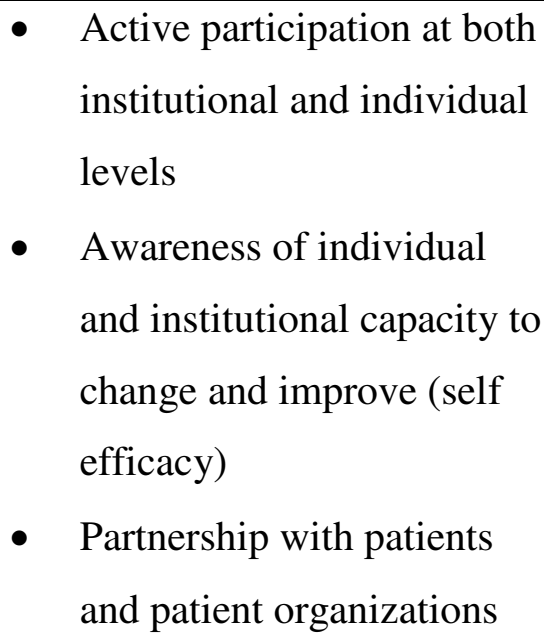 \\
\hline
\end{tabular}


Figure. Five-step process for developing a patient empowerment program

\section{Ownership: develop a culture of accountability and shared responsibility}

\begin{tabular}{|l|l|}
\hline $\begin{array}{l}\text { Make sure that a multimodal hand hygiene } \\
\text { promotion strategy is in place at your } \\
\text { institution (see Table) }\end{array}$ \\
$\begin{array}{l}\text { Introduce patient empowerment to key } \\
\text { decision-makers in the context of hand } \\
\text { hygiene improvement }\end{array}$ \\
$\begin{array}{l}\text { Determine the most appropriate terminology } \\
\text { to describe empowerment in your culture or } \\
\text { community }\end{array}$ \\
Establish your core support network \\
\hline
\end{tabular}

\section{Review existing empowerment models/programs}

\begin{tabular}{|l|}
\hline \\
Research existing empowerment programs \\
for information on how they are structured \\
and implemented. Four types are listed here: \\
Educational \\
Motivational \\
Role +modeling \\
Multifaceted
\end{tabular}

\section{Program development: know your organization}

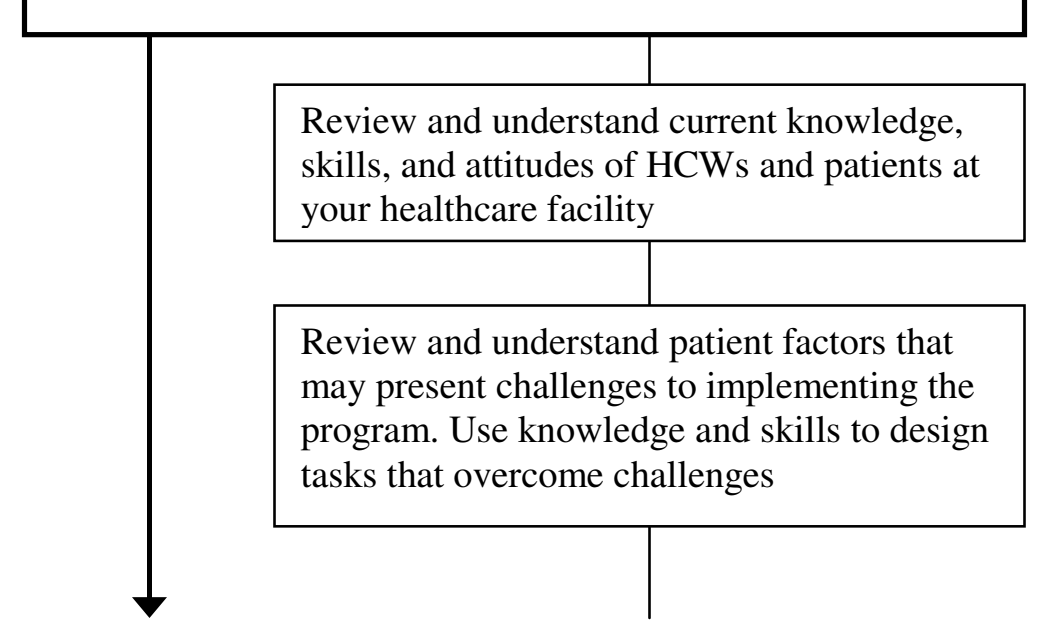


(from previous page)

Review and understand HCW factors that may present challenges to implementing the program. Use knowledge and skills to design tasks that overcome challenges

Plan and develop educational materials based on your organization's norms

\section{Program implementation}

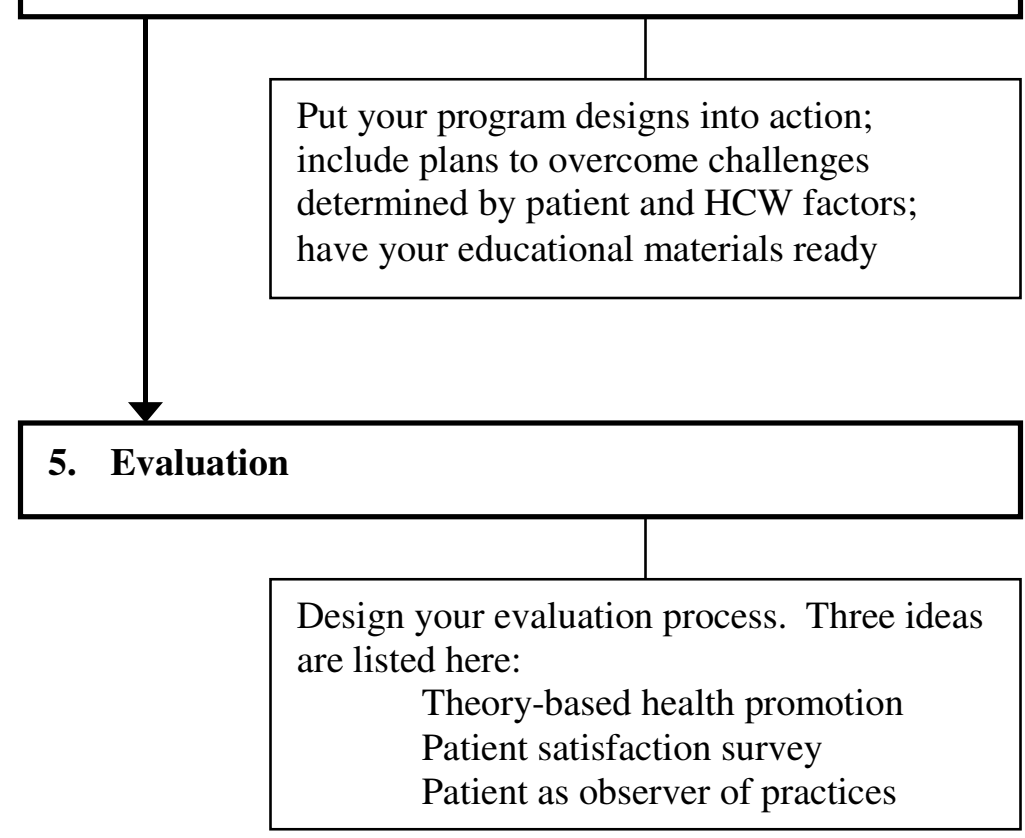

A detailed template of a strategy and resources to develop an empowerment program is available in the WHO Guidelines on Hand Hygiene in Healthcare (2009) Table V.7.1, p.204 available at:

http://whqlibdoc.who.int/publications/2009/9789241597 906_eng.pdf 
